CLINICAL STUDY

\title{
Improving glucocorticoid replacement therapy using a novel modified-release hydrocortisone tablet: a pharmacokinetic study
}

\author{
Gudmundur Johannsson $^{1}$, Ragnhildur Bergthorsdottir ${ }^{1}$, Anna G Nilsson ${ }^{1}$, Hans Lennernas ${ }^{3}$, Thomas Hedner ${ }^{2}$ \\ and Stanko Skrtic ${ }^{2}$ \\ Departments of ${ }^{1}$ Endocrinology, Sahlgrenska Academy, Sahlgrenska University Hospital, Grona Straket 8 and ${ }^{2}$ Clinical Pharmacology, Sahlgrenska \\ Academy, Gothenburg University, SE-413 45 Gothenburg, Sweden and ${ }^{3}$ Department of Pharmaceutics, Uppsala University, SE-751 23 Uppsala, Sweden \\ (Correspondence should be addressed to G Johannsson; Email: gudmundurjohannsson@gu.se)
}

\begin{abstract}
Background: Endogenous plasma cortisol levels have a well-defined circadian rhythm. The aim of this project is to develop a once daily oral dual-release formulation for cortisol replacement therapy that mimics the diurnal variation in the plasma cortisol profile.

Objective: To determine single-dose plasma pharmacokinetics and dose-proportionality of oral 5 and $20 \mathrm{mg}$ dual-release hydrocortisone tablets in healthy volunteers. In addition, the effect of food intake was investigated for the $20 \mathrm{mg}$ dose.

Design: A randomised, controlled, two-way cross-over, double-blind, phase I study of oral hydrocortisone (modified (dual) release; 5 and $20 \mathrm{mg}$ ) with an open food-interaction arm.

Methods: The single dose pharmacokinetic studies were performed with betamethasone suppression. The two first study days were blinded and randomised between morning administration of 5 and $20 \mathrm{mg}$ tablet in a fasting state. The third day was open with a $20 \mathrm{mg}$ tablet taken $30 \mathrm{~min}$ after a highcalorie, high-fat meal. The plasma samples were assayed using both a validated LC-MS/MS and an immunoassay. The plasma pharmacokinetic variables were calculated using non-compartmental data analysis.

Results: The time to reach a clinically significant plasma concentration of cortisol $(>200 \mathrm{nmol} / \mathrm{l})$ was within $20 \mathrm{~min}$ and a mean peak of 431 (s.D. 126) nmol/l was obtained within $50 \mathrm{~min}$ after administration of the $20 \mathrm{mg}$ tablet. Plasma cortisol levels remained above $200 \mathrm{nmol} / \mathrm{l}$ for around $6 \mathrm{~h}$ thereafter and all plasma concentrations $18-24 \mathrm{~h}$ after intake were below $50 \mathrm{nmol} / \mathrm{l}$. In the fed state the time to reach $200 \mathrm{nmol} / \mathrm{l}$ was delayed by 28 and 9 min based on LC-MS/MS and immunoassay, respectively. The 5 and $20 \mathrm{mg}$ tablets produced an increase in plasma exposure of cortisol that was not fully dose proportional.

Conclusion: The dual release hydrocortisone tablet with once-daily administration produced a diurnal plasma cortisol profile mimicking the physiological serum cortisol profile.
\end{abstract}

European Journal of Endocrinology 161 119-130

\section{Introduction}

Glucocorticoids (GC) are important steroids for intermediary metabolism, immune function, musculoskeletal function, connective tissue and brain function. GC deficiency occurs in adrenal insufficiency (AI), which can be primary (Addison's disease), secondary (central) due to hypopituitarism or tertiary due to a suppressed hypothalamic-pituitary-adrenal (HPA) axis after longterm high-dose GC treatment. In the 1950s, before the availability of GCs, the 2-year mortality rate in patients with Addison's disease was more than $80 \%$ (1), demonstrating the importance of this steroid for health and survival.
The outcome of GC replacement therapy has been considered satisfactory (2) until recently. Patients with hypopituitarism have double the standardised mortality rate (SMR) $(3,4)$ and young adults with hypopituitarism and concomitant AI have more than 7 -fold expected mortality rate (5). Moreover, patients with Addison's disease have also shown to have more than double the SMR $(6,7)$. A possible explanation for this increased mortality rate is an inappropriate GC replacement therapy; i.e. both too high-maintenance doses and an inadequate GC exposure in response to stress and concurrent illnesses. Thorough re-evaluations of patients receiving GC replacement therapy have revealed that doses are too high and can be reduced in a majority 
of patients (8). In addition, an attenuated diurnal variation in the plasma cortisol profile has been associated with abdominal obesity and metabolic syndrome $(9,10)$. It is therefore likely that many patients are receiving overly high oral doses delivered with an unphysiological plasma concentration-time profile.

In an early attempt to improve well-being of patients with AI, Groves et al. increased the frequency of hydrocortisone oral administration from twice to thrice daily with the same daily dose in a small subset of patients and managed to improve their well-being, particularly during midday and afternoon (11). Recent studies have demonstrated that well-being and quality of life is compromised in patients with both primary and secondary AI (12-14). In a study, there was an association between high oral replacement doses of GC and poor scoring in quality of life questionnaires (12). In a recent study using a subcutaneous infusion pump to re-establish the physiological circadian rhythm of cortisol, patients were able to reduce their total daily doses while experiencing improved levels of subjective health and well-being (15). It is therefore likely that the pattern of hydrocortisone delivery and the total plasma cortisol exposure profile are of importance for patient outcome.

Hydrocortisone is the pharmaceutical name of the endogenous active steroid cortisol. Orally administered hydrocortisone is the most commonly used GC for cortisol replacement therapy $(16,17)$. This also means that the obtained plasma concentration-time profile of hydrocortisone in replacement therapy directly reflects the pharmacodynamic profile of the endogenous hormone cortisol (18).

We have developed a novel, once daily, modified release hydrocortisone tablet with combined immediate and extended release characteristics in order to obtain a more physiological plasma cortisol profile. The overall aim of this oral formulation is to simplify GC replacement, improve physiological GC replacement therapy and outcome, and improve compliance and safety of this treatment. The aim of this study was to investigate single-dose pharmacokinetics and doseproportionality of oral 5 and $20 \mathrm{mg}$ modified-release hydrocortisone tablets during fasting and fed conditions in healthy volunteers. The plasma pharmacokinetic variables were calculated from data obtained with a selective analytical method, i.e. LC-MS/MS. Plasma samples were also assayed using an immunoassay method for comparison.

\section{Subjects and methods}

This was a randomised, controlled, two-way cross-over, double-blind study of oral hydrocortisone modified release tablets ( 5 and $20 \mathrm{mg}$ ) with an open food-drug interaction arm in healthy volunteers (Fig. 1). The study protocol was approved by the Ethics Committee at the

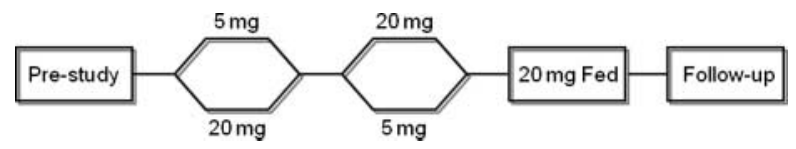

Figure 1 Study design. The study was as a randomised two period cross-over trial. The study will use the oral modified-release treatments of 5 and $20 \mathrm{mg}$ hydrocortisone given to healthy volunteers in random order. The study periods were separated by wash-out periods of at least $24 \mathrm{~h}$. A subset of the healthy volunteer received the $20 \mathrm{mg}$ dose concomitantly with food after the second cross-over period, with a wash-out period of at least $24 \mathrm{~h}$. At pre-entry, the subjects will be investigated for eligibility for the study within $10 \pm 5$ days before the first study day. A safety follow-up was performed 2-10 days after the last dose.

Sahlgrenska Academy and by the Swedish Medical Product Agency, Uppsala, Sweden, and performed according to the principles of Good Clinical Practice (CPMP/ICH/135/95) and the Declaration of Helsinki. All volunteers gave written, informed consent before entering the study.

\section{Study participants}

Healthy male $(n=9)$ and female $(n=7)$ volunteers were assessed for eligibility at a pre-study screening visit. Participants were eligible if they were aged 18-65 years, with a body mass index (BMI) between 18 and $27 \mathrm{~kg} / \mathrm{m}^{2}$. All participants were required to have vital signs within normal ranges. Participants were asked to use contraceptive methods for the duration of the study. The demographics of participants entering the study are shown in Table 1.

The medical history of the participants was assessed at the screening visit, paying particular attention to any previous metabolic or endocrine disorders, infective episode or any underlying disease that may need regular or periodic treatment with GCs. Volunteers were excluded from the study if they showed any clinically significant abnormalities in pre-study safety laboratory tests.

Other exclusion criteria were as follows: any medication or agents that may interfere with any pharmacokinetic properties of hydrocortisone within 14 days prior to study start, such as ritonavir, carbamazepine, rifampicin, ketoconazole, grapefruit juice, St John's Wort and other herbal and pharmaceutical drugs. Further exclusion criteria were: history of hydrocortisone intolerance or severe allergic disease; administration of other investigational drugs within 8 weeks preceding the pre-entry examination; alcohol/ drug abuse or any condition associated with poor healthy volunteer compliance, including expected noncooperation, as judged by the investigator.

\section{Interventions}

The study was conducted as a randomised, two-period, cross-over, single-dose, double-blind trial in 16 healthy volunteers. The study used the oral modified-release 
Table 1 Summary of baseline demographics for participants in the study.

\begin{tabular}{|c|c|c|c|}
\hline Demographics & & $\begin{array}{c}n=16 \\
\text { ITT population }\end{array}$ & $\begin{array}{c}n=14 \\
\text { PP population }\end{array}$ \\
\hline Age (years) & $\begin{array}{l}5 \mathrm{mg} \\
20 \mathrm{mg}\end{array}$ & $\begin{array}{l}25.7(3.3) \\
25.3(20.3-32.0)\end{array}$ & $\begin{array}{l}25.5(3.4) \\
24.9(20.3-32.0)\end{array}$ \\
\hline Male & & $9(56.3 \%)$ & $9(64.3 \%)$ \\
\hline \multicolumn{4}{|l|}{ Baseline variables } \\
\hline Height & $\begin{array}{l}5 \mathrm{mg} \\
20 \mathrm{mg}\end{array}$ & $\begin{array}{l}175.5(9.9) \\
176.5(160.0-188.0)\end{array}$ & $\begin{array}{l}177.3(9.2) \\
178.5(162.0-188.0)\end{array}$ \\
\hline Weight & $\begin{array}{l}5 \mathrm{mg} \\
20 \mathrm{mg}\end{array}$ & $\begin{array}{l}68.3(10.2) \\
68.5(53.1-82.4)\end{array}$ & $\begin{array}{l}70.1(9.7) \\
71.5(53.1-82.4)\end{array}$ \\
\hline Body mass index (BMI) & $\begin{array}{l}5 \mathrm{mg} \\
20 \mathrm{mg}\end{array}$ & $\begin{array}{l}22.1(2.5) \\
22.3(18.3-26.3)\end{array}$ & $\begin{array}{l}22.3(2.6) \\
22.7(18.3-26.3)\end{array}$ \\
\hline $\begin{array}{l}\text { Tobacco user } \\
\text { Current medication }\end{array}$ & & $\begin{array}{l}3(18.8 \%) \\
5(31.3 \%)\end{array}$ & $\begin{array}{l}2(14.3 \%) \\
3(21.4 \%)\end{array}$ \\
\hline Diseases & & $0(0.0 \%)$ & $0(0.0 \%)$ \\
\hline
\end{tabular}

Data is presented in mean (s.D.)/median (min-max) or $n$ (\%). ITT, intention to treat population and PP, per protocol population.

treatments of 5 and $20 \mathrm{mg}$ hydrocortisone given in random order at study periods $A$ and $B$. The study periods were separated by wash-out, a period of at least $24 \mathrm{~h}$. At pre-entry, the subjects had undergone a full clinical examination including medical history, physical examination, blood pressure, heart rate, ECG, and routine clinical chemistry and haematology measurements within $10 \pm 5$ days before the first study day. A safety follow-up, including physical examination, routine clinical chemistry and haematology was performed 2-14 days after the last dose.

Subsequently, the same healthy volunteers as in study periods A and B received the $20 \mathrm{mg}$ dose concomitantly with food at a separate occasion, with a wash-out period of at least $24 \mathrm{~h}$. This was in order to study the effect of food on the plasma pharmacokinetics of the study drug.

The endogenous cortisol secretion was suppressed using betamethasone in order to be able to measure plasma pharmacokinetics of the preparations to be used. Betamethasone was orally administrated in the dose of $1 \mathrm{mg}$ at $0600 \mathrm{~h}$ and at $2300 \mathrm{~h}$, the night before the study day and at 0700, 1100, 1700 and $2300 \mathrm{~h}$ on the day of delivery of the study drug. This would assure undetectable levels of endogenous plasma cortisol in most healthy adults. Subjects with plasma concentrations of more than $50 \mathrm{nmol} / \mathrm{l}$ at any of the baseline samplings were not eligible for analysis.

The healthy volunteer arrived at $0700 \mathrm{~h}$ having fasted since $2200 \mathrm{~h}$ the previous day (no intake of solids, but water ad libitum). Indwelling cannulas for blood sampling were inserted in both forearm veins and secured. After collection of reference blood samples, the dual release hydrocortisone tablets were swallowed together with $240 \mathrm{ml}$ water with the subject sitting in an upright body position for at least 30 min post dose. In the fasting treatment, the subjects would remain fasting for $4 \mathrm{~h}$ post dose administration. Pharmacokinetic plasma samples were taken at regular pre-specified intervals. Measurement of plasma sodium, potassium and plasma glucose concentrations were performed on the reference plasma samples during the same day for safety reasons.

The healthy volunteers remained in the laboratory for $\sim 14 \mathrm{~h}$. Standardised meals were served at pre-specified times (lunch $4-5 \mathrm{~h}$ post dose and dinner $6.7-8 \mathrm{~h}$ post dose). Each healthy volunteer would consume the same quantity of food (one serving of a ready meal containing $396 \mathrm{kcal}$ of which $6 \% \mathrm{w} / \mathrm{w}$ derived from protein, $9 \% \mathrm{w} /{ }_{\mathrm{w}}$ from carbohydrates and $3 \% \mathrm{w} / \mathrm{w}$ from fat) and drink ( $3 \mathrm{dl}$ milk or water and $1.5 \mathrm{dl}$ of coffee or tea) during the study days except for the first 60 min post study drug administration. The subjects were also instructed to refrain from consuming grapefruit, grapefruit juice, liquorice or sevilla orange $72 \mathrm{~h}$ before dosing until the end of the trial.

In the fed state, the subjects consumed a standardised high-fat, high-calorie breakfast in less than $30 \mathrm{~min}$ and at least $30 \mathrm{~min}$ prior to study drug administration. The breakfast contained $\sim 150,250$, and 500-600 calories from protein, carbohydrate and fat, respectively (http://www.fda.gov/cder/guidance/5194fnl.pdf).

Blood samples $(7 \mathrm{ml}$ each) for determination of hydrocortisone in plasma were collected at predetermined time-points on each study day. Blood samples for plasma pharmacokinetics were taken at pre-dose $(-30)$, and at $0,5,10,15,20,25,30,45,60,90$, 120, 180, 240, 300, 360, 480, 600, 720, 840, 1440 and 1470 min post dose.

Tolerability and safety parameters such as blood pressure and heart rate were followed during the complete study day and plasma glucose was monitored before and at the end of each study day. Tolerability (subjective discomfort) was assessed by questionnaires completed at the end of each study day.

\section{Pharmaceutical formulation}

A novel oral modified release formulation (dual release) in two different strengths was used in this pharmacokinetic study (DuoCort AB, Helsingborg, Sweden). 
In principle, the formulation consists of one extended release core that is surrounded by an immediate release coating. The intention is that the immediate release part will be released and absorbed rapidly, as hydrocortisone has a high intestinal permeability. The remaining hydrocortisone will then be released from the controlled release part of the dosage form at a slower rate throughout the small and large intestine (19).

\section{Assessments}

Demographic and medical history data were recorded at the pre-study visit. Participants were monitored continuously during the study for the occurrence of adverse events (AEs), noting the duration, severity and relationship to the study drug.

\section{Assays}

All plasma samples were stored in $-20{ }^{\circ} \mathrm{C}$ until analysis and performed in one run. Plasma cortisol was measured using a GLP validated HPLC-MS/MS assay with an assay range of $2.76-1380 \mathrm{nmol} / \mathrm{l}$. The assay was validated according to linearity, selectivity, accuracy, precision, recovery and stability (20). As an internal standard an isotope labelled $\mathrm{D}_{4}$-cortisol was used. The limit of quantification (LOQ) was $2.7 \mathrm{nmol} / \mathrm{l}$. The intra-assay coefficient of variation (CV) was $2.0 \%$. Plasma cortisol was also measured using a validated immunoassay at a certified university hospital clinical chemistry laboratory, using Cortisol Cal Set (Roche) as the calibrant on a Hitachi Modular E automated analytical system with an assay range of $2-1750 \mathrm{nmol} / \mathrm{l}$, with a lower limit of detection of $0.5 \mathrm{nmol} / \mathrm{l}$. The intra-assay CV was $3.0 \%$.

\section{Pharmacokinetic data and statistical analyses}

All participants who received at least one dose of study drug were included in the safety population. All data from the 14 subjects who received all three doses were included in the pharmacokinetic data analysis.

Pharmacokinetic variables for hydrocortisone (cortisol) were calculated using a non-compartmental analysis by using the WinNonlin 5.2 (Pharsight Corp., Mountain View, CA, USA). The observed plasma concentrations at $15 \mathrm{~min}\left(C_{0.25} \mathrm{~h}\right)$ and the first maximal value $\left(C_{\max }\right)$ respectively were derived directly from the plasma-concentration data for each healthy volunteer. In addition, the time to reach $200 \mathrm{nmol} / \mathrm{l}\left(T_{200}\right)$ and the time to reach $C_{\max }\left(T_{\max }\right)$ were also derived directly from the individual plasma profile. $T_{200}$ was derived by interpolation directly from each individual plasma concentration-time profile. Due to the bi-phasic plasma concentration profile two $C_{\max }$ and $T_{\max }$ values were described in some individuals and were derived directly from each plasma profile.
The area under the plasma concentration-time curve (AUC) was calculated by the linear/logarithmic trapezoidal method, more exactly when the measurement for time $t+1$ was greater than or equal to the measurement at time $t$, then linear trapezoidal rule was used and when the opposite occurred the logarithmic trapezoidal rule was used. $\mathrm{AUC}_{(0-24 \mathrm{~h})}$ was calculated from time zero to the last measurable concentration point (Clast). $\mathrm{AUC}_{(0-\text {-infinity })}$ was calculated by extrapolating the curve to infinity by adding Clast, extrapolated $/ \lambda z$ to $\mathrm{AUC}_{(0-6 \mathrm{~h})} . \lambda z$ is the first-order elimination rate constant estimated from at least five of the last measurable concentrations in the interval 5-24 h. The terminal half-life (T1/2) was obtained from the elimination rate constant as $\ln 2 / \lambda z$. The terminal half-life was calculated in two intervals: $5-14 \mathrm{~h}$ (T1/2 5-14) and 5-24 h (T1/2 5-24). The residual area from the last observed data point to infinite time was obtained by linear extrapolation of values from $5 \mathrm{~h}$ and forward, i.e. by dividing the last predicted concentration by the terminal rate constant obtained by linear regression analysis of the time points from $5 \mathrm{~h}$ and forward.

Plasma concentrations below lower LOQ were excluded from the pharmacokinetic calculations. However, at time points prior to $C_{\max }$, plasma concentrations below LOQ were taken as zero in the calculations. Furthermore, if there was more than one plasma concentration below LOQ prior to $C_{\max }$, the last concentration before the first quantifiable plasma concentration was calculated as $\mathrm{LOQ} / 2$.

The pharmacokinetic variables, i.e. plasma cortisol concentrations, were calculated using baseline corrected values, which was defined as the average of the -30 and 0 min value subtracted from every plasma cortisol concentration value.

All pharmacokinetic variables, except for $T_{\max }$ and $T_{200}$, are presented as geometric mean and $95 \%$ confidence interval, while $T_{\max }$ and $T_{200}$ are reported as median and range.

\section{Results}

\section{Study participants}

Of 16 included and randomised subjects, a total of 14 completed all three visits. Two subjects completed only a first study day. One subject was excluded due to inability to suppress endogenous cortisol levels below the predefined level of $50 \mathrm{nmol} / \mathrm{l}$ and the other discontinued the trial due to poor compliance. Fourteen subjects are included in the efficacy analysis and 16 in the safety analysis.

All study participants were Caucasian, had a mean age of $25.5 \pm 3.4$ years and a mean BMI of $22.3 \pm 2.6 \mathrm{~kg} / \mathrm{m}^{2}$. The two groups randomised to 5 and $20 \mathrm{mg}$ respectively, were similar in terms of baseline demographic characteristics as shown in Table 1. 


\section{Safety}

Number of AE during $5 \mathrm{mg}$ fasted, $20 \mathrm{mg}$ fasted and $20 \mathrm{mg}$ fed treatments were 18, 17 and 19 cases respectively. Recorded AEs were of a mild and transient nature and predominantly procedure related, such as cannula related haematomas and transient low haemoglobin values, none of which were dose-related. No SAEs occurred during the trial.

From the questionnaires recorded for $5 \mathrm{mg}, 20 \mathrm{mg}$ fasted and $20 \mathrm{mg}$ with food, it could be noted that most of the subjects felt well during the treatment periods. At the end of each $24 \mathrm{~h}$ treatment day, a small proportion of subjects felt worse and/or noticed minor changes in general well-being.

\section{Plasma pharmacokinetics of modified release hydrocortisone tablets: 5 and 20 mg in fasted state}

The individual and mean plasma concentration-time profiles and corresponding pharmacokinetic variables of hydrocortisone following a single dose of this novel dual release tablet for all three groups are reported in Figs 2-4 and Table 2 respectively. It is important to recognise that the pharmacokinetic variables of hydrocortisone in this study were calculated based on plasma concentrations determined with a highly selective LC-MS/MS analytical method. The plasma $\mathrm{AUC}_{(0-24 \mathrm{~h})}$ for the 5 and $20 \mathrm{mg}$ treatments administered in the fasting state were 834.0 (578.1-1089.9) and 2404.7 (1727.1-3082.7) nmol h/l respectively (Fig. 5). The dose corrected plasma $\mathrm{AUC}_{(0-24 \mathrm{~h})}$ values $\left(\mathrm{AUC}_{(0-24 \mathrm{~h})} /\right.$ dose $)$ were 166.8 (115.6-218.0) and 120.2 (86.4-154.1) for the 5 and $20 \mathrm{mg}$ doses respectively. The mean $C_{\max }$ was

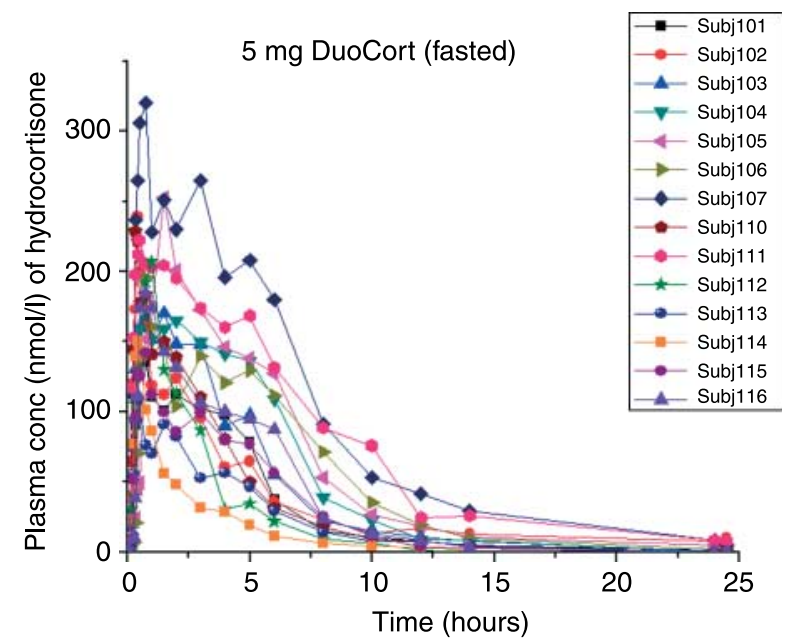

Figure 2 Individual and mean plasma concentration-time profile for hydrocortisone in healthy subjects $(n=14)$ after a single oral administration of novel modified dosage form of $5 \mathrm{mg}$ in the fasted state. Endogenous cortisol secretion was suppressed using betamethasone. Each plasma concentration is determined with a selective LC-MS/MS method and has been corrected for background cortisol levels.

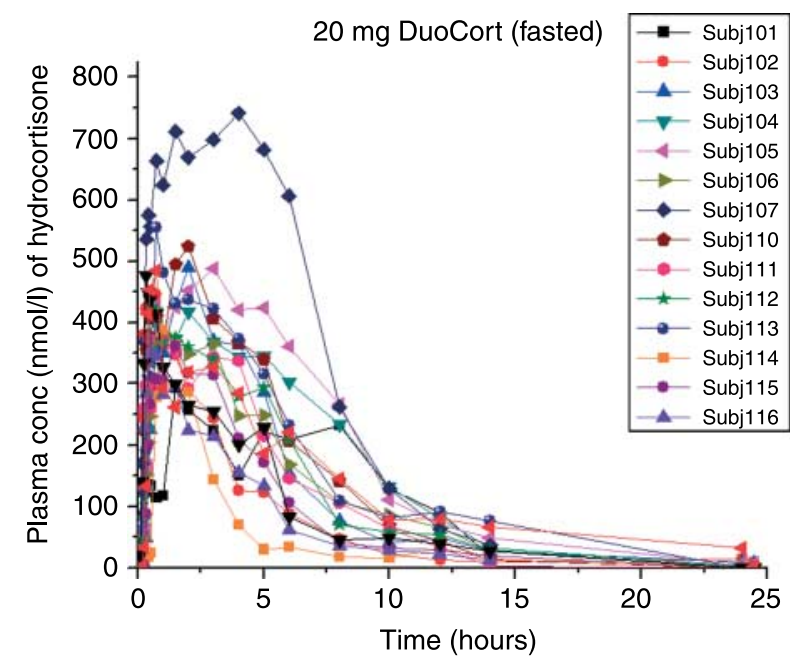

Figure 3 Individual and mean plasma concentration-time profile for hydrocortisone in healthy subjects $(n=14)$ after a single oral administration of novel modified dosage form of $20 \mathrm{mg}$ in the fasted state. Endogenous cortisol secretion was suppressed using betamethasone. Each plasma concentration is determined with a selective LC-MS/MS method and has been corrected for background cortisol levels.

188.4 (159.4-217.4) and 403.7 (337.8-469.6) nmol/l for 5 and $20 \mathrm{mg}$ respectively. The dose corrected plasma $C_{\max }$ values $\left(C_{\max } /\right.$ dose $)$ were $37.7(31.9-43.5)$ and 20.2 (16.9-23.5) for the 5 and $20 \mathrm{mg}$ dose $(P<0.001)$ respectively. This is in accordance with the effect of dose on plasma AUC and supports the hypothesis of a lower absorption rate of the $20 \mathrm{mg}$ dose in the fasted state.

The time to reach $200 \mathrm{nmol} \mathrm{h/l}$ in plasma, which is a clinical active concentration, was 36.2 (17.7-90) and $20.5(8.7-72.3) \mathrm{min}$ for the 5 and $20 \mathrm{mg}$ treatment respectively. The plasma concentration at $0.25 \mathrm{~h}\left(C_{0.25 \mathrm{~h}}\right)$ was $50.5(25.7-75.3) \mathrm{nmol} / \mathrm{l}$ for $5 \mathrm{mg}$ compared with $74.0(4.81-143.3) \mathrm{nmol} / \mathrm{l}$ for the $20 \mathrm{mg}$ treatment. There was no difference in time $\left(T_{\max }\right)$ to $C_{\max }$ in the fasting state between the two doses. It was 45 (20-90) and 45 (20-120) min for the 5 and $20 \mathrm{mg}$ treatments respectively.

The plasma concentration-time profile had double peaks in some fasted and fed subjects most likely due to the dual nature of drug release from the modified release tablet (Figs 2-4). The numbers of subjects with double peak were 5,5 and 8 for the $5 \mathrm{mg}$ (fasted), $20 \mathrm{mg}$ (fasted) and $20 \mathrm{mg}$ (fed) respectively.

The terminal half-life calculated from the interval 5-14 h was $2.47(2.11-2.83)$ and 3.25 (2.04-4.46) h for the 5 and $20 \mathrm{mg}$ dose respectively. The terminal halflife calculated from the interval $5-24 \mathrm{~h}$ was 2.80 (1.83-3.77) and $3.90(0-8.90) \mathrm{h}$ for the 5 and $20 \mathrm{mg}$ dose respectively. The extrapolated area (\%) in the plasma concentration-time profile was low for both doses, $0.85 \%(0-2.21)$ and $1.06 \%(0-9.63)$ for 5 and $20 \mathrm{mg}$ respectively, which clearly demonstrates that there is no risk of accumulation of this modified release product during repeated oral replacement therapy. 


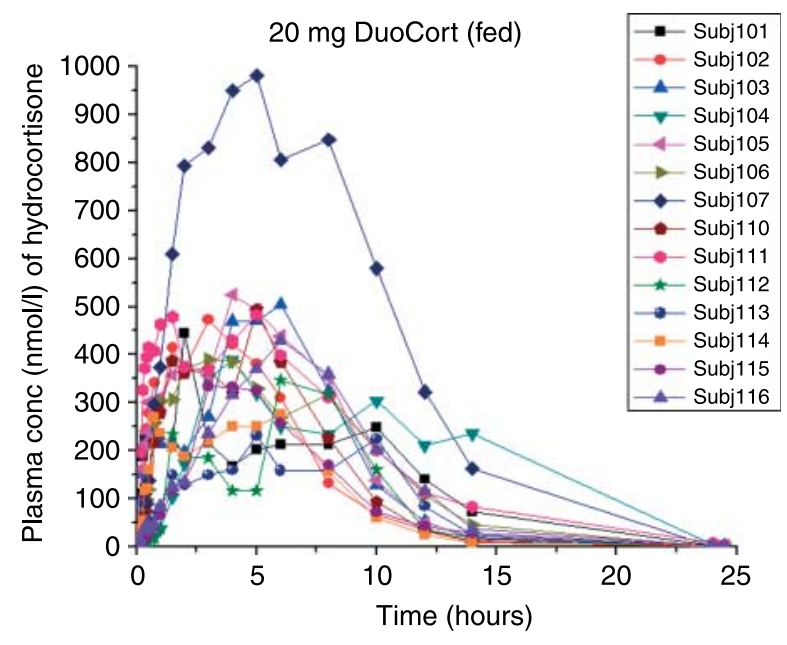

Figure 4 Individual and mean plasma concentration-time profile for hydrocortisone in healthy subjects $(n=14)$ after a single oral administration of novel modified dosage form of $20 \mathrm{mg}$ in the fed state. Endogenous cortisol secretion was suppressed using betamethasone. Each plasma concentration is determined with a selective LC-MS/MS method and has been corrected for background cortisol levels.

The longer half-life for the wider time interval (5-24 h) was due to the endogenous background values of cortisol. If subject 111, who had a terminal half-life and extrapolated area of $38.7 \mathrm{~h}$ and $58.4 \%$, were deleted, the new mean values of terminal half-life, $\mathrm{AUC}_{(0-\text { infinity })}$ and extrapolated area for the $20 \mathrm{mg}$ dose would be 3.22 (2.44-4.0) h, 2383 (1688.1-3078.1) nmol h/l and 0.72 (0-2.0) \% (within brackets in Table 2).

\section{Food-drug interaction study: 20 mg fasted versus $20 \mathrm{mg}$ with a high caloric meal}

The $\mathrm{AUC}_{(0-24 \mathrm{~h})}$ increased to $3234.2(0-6481.8)$ $\mathrm{nmol} \mathrm{h} / \mathrm{l}$ when $20 \mathrm{mg}$ of this novel modified release tablet was administered $30 \mathrm{~min}$ after food intake as compared with when the tablet was administered in the fasting state 2404.7 (1727.1-3082.2) $\mathrm{nmol} \mathrm{h/l}$ $(P=0.0001)$. The dose corrected plasma $\mathrm{AUC}_{(0-24 \mathrm{~h})}$ values $\left(\mathrm{AUC}_{(0-24 \mathrm{~h})} /\right.$ dose $)$ were $161.7(0-324.1)$ and 120.2 (86.4-154.1) for the $20 \mathrm{mg}$ fed and $20 \mathrm{mg}$ fasted dose respectively (Table 2 ).

The plasma $C_{\max }$ was similar following administration of $20 \mathrm{mg}$ in fed state, $364(0-740.1) \mathrm{nmol} / \mathrm{l}$, compared with $403.7(337.8-469.6) \mathrm{nmol} / \mathrm{l}$ for the $20 \mathrm{mg}$ treatment in fasted state. The dose corrected plasma $C_{\max }$ values $\left(C_{\max } /\right.$ dose $)$ were $18.2(0-37.0)$ and 20.2 (16.9-23.5) for the $20 \mathrm{mg}$ fed and $20 \mathrm{mg}$ fasted dose respectively. The time to maximal plasma concentration was longer for $20 \mathrm{mg}$ administered $30 \mathrm{~min}$ after food intake to $135(25-360) \mathrm{min}$ compared with $45(20-120)$ min for the $20 \mathrm{mg}$ dose in the fasting state $(P<0.01)$.

The time to reach $200 \mathrm{nmol} / \mathrm{l}$ was 39.8 (9.4-266) min in the fed state, which is significantly longer $(P>0.01)$ than $20.3(8.7-72.3) \mathrm{min}$ for the $20 \mathrm{mg}$ dose in the fasted state.

The terminal half-life calculated from the interval $5-14 \mathrm{~h}$ was $3.18(0.19-6.16)$ and 3.25 (2.01-4.46) $\mathrm{h}$ for the fed and fasted state respectively. The terminal half-life calculated from the interval 5-24 h was $2.64(0.02-5.26)$ and $3.90(0-8.90) \mathrm{h}$ for the fed and fasted state respectively. The extrapolated area in the fed state was $1.25(0-2.57)$ $\%$, which shows that there is no tendency of dose accumulation for this once daily modified release tablet in the fed state.

\section{Pharmacokinetic variables of hydrocortisone from plasma samples analysed using an immunoassay}

The pharmacokinetic variables and plasma concentration-time profiles of hydrocortisone analysed with an immunoassay and selective LC-MS/MS methods

Table 2 Plasma pharmacokinetic variables of hydrocortisone following oral single dose administration of a novel dosage form (5 and $20 \mathrm{mg})$ in fasted $(5$ and $20 \mathrm{mg})$ and fed state $(20 \mathrm{mg})$ in healthy subjects $(n=14)$. The calculations of the pharmacokinetic variables are based on plasma concentrations determined with a selective LC-MS/MS method. All pharmacokinetic variables, except for $T_{\max }$ and $T_{200}$, are presented as geometric mean and 95\% confidence interval, while $T_{\max }$ and $T_{200}$ are reported as median and range.

\begin{tabular}{|c|c|c|c|}
\hline & 5 mg (fasted) & $20 \mathrm{mg}$ (fasted) & $20 \mathrm{mg}$ (fed) \\
\hline $\mathrm{AUC}_{(0-24 \mathrm{~h})}(\mathrm{nmol} \mathrm{h} / \mathrm{l})$ & $834.0(578.1-1089.9)$ & $2404.7^{\mathrm{a}}(1727.1-3082.2)$ & $3234.2^{\mathrm{a}}(0-6481.8)$ \\
\hline$C_{\max }(\mathrm{nmol} / \mathrm{l})$ & $188.4(159.4-217.4)$ & $403.7(337.8-469.6)$ & $364.0(0-740.1)$ \\
\hline$C(0.25 \mathrm{~h})(\mathrm{nmol} / \mathrm{l})$ & $50.5(25.7-75.3)$ & $74.0(4.81-143.3)$ & $34.2(4.21-64.2)$ \\
\hline$T_{\max }(\min )$ & $45^{\mathrm{b}}(20-90)$ & $45^{\mathrm{c}}(20-120)$ & $135^{\mathrm{b}, \mathrm{c}}(25-360)$ \\
\hline$T(200 \mathrm{nmol} / \mathrm{l})(\min )$ & $36.2(17.7-90)$ & $20.5^{\mathrm{d}}(8.7-72.3)$ & $48.3^{d}(9.4-266)$ \\
\hline Terminal half-life 5-24 h (h) & $2.80(1.83-3.77)$ & $\begin{array}{c}3.90^{\dagger}(0-8.90) \\
3.22(2.44-4.0)\end{array}$ & $2.64(0.02-5.26)$ \\
\hline Terminal half-life $5-14 \mathrm{~h}(\mathrm{~h})$ & $2.47(2.11-2.83)$ & $3.25(2.04-4.46)$ & $3.18(0.19-6.16)$ \\
\hline $\mathrm{AUC}_{(0-\text { infinity })}(\mathrm{nmol} \mathrm{h} / \mathrm{l})$ & $853.2(593.6-1112.9)$ & $\begin{array}{r}2665.5^{\dagger}(1408.0-3923.0) \\
2383(1688.1-3078.1)\end{array}$ & $3340.7(0-6702.1)$ \\
\hline$\%$ extrapolated area under curve (\%) & $0.85(0-2.21)$ & $\begin{array}{l}1.06^{\dagger}(0-9.03) \\
0.76(0-2.0)\end{array}$ & $1.25(0-2.57)$ \\
\hline
\end{tabular}

${ }^{\mathrm{a}} \mathrm{P}<0.001 ;{ }^{\mathrm{b}} \mathrm{P}<0.001 ;{ }^{\mathrm{c}} \mathrm{P}<0.01,{ }^{\mathrm{d}} \mathrm{P}<0.01$ (groups with the same letter in the suffix are different). ${ }^{\mathrm{t}}$ Terminal half-life of $38.7 \mathrm{~h}$, AUC $(0-$ infinity) of 2665.5 and extrapolated area of $58.4 \%$ in subject 111 . New values given in brackets. 


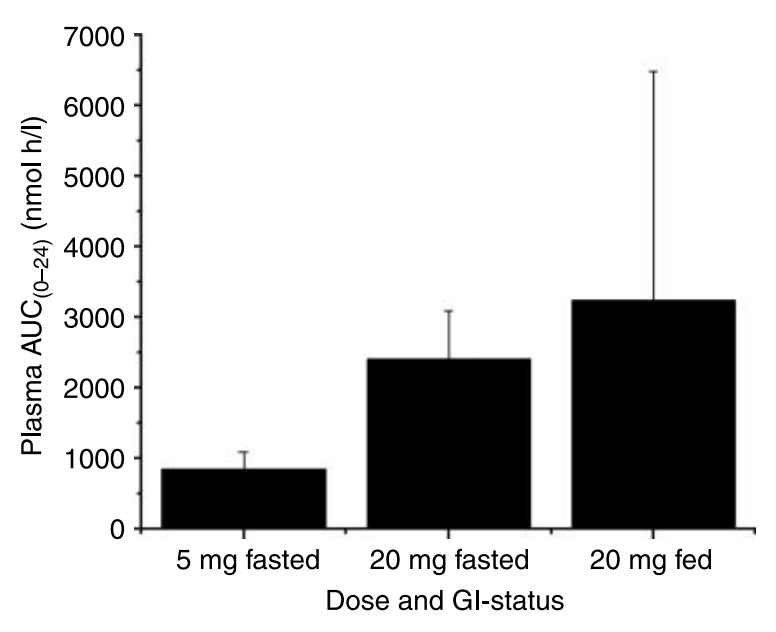

Figure 5 The mean \pm s.D. plasma $\mathrm{AUC}_{0-24}$ for hydrocortisone in healthy subjects $(n=14)$ after single oral administration of novel modified dosage form of $5 \mathrm{mg}$ (fasted), $20 \mathrm{mg}$ (fasted) and $20 \mathrm{mg}$ (fed). The plasma $\mathrm{AUC}_{0-24}$ is based on plasma cortisol being analysed using a selective LC-MS/MS method.

are shown in Table 3 and Figs 6-8. The general trend was that the plasma AUC ratio for the immunoassay and LC-MS/MS methods ( $\mathrm{AUC}_{\text {immuno }}$ / $\mathrm{AUC}_{\mathrm{LC}-\mathrm{MS} / \mathrm{MS}}$ ) for the 5 and $20 \mathrm{mg}$ dose in the fasted state increased from $41 \pm 21$ to $52 \pm 11 \%(P<0.01)$ respectively. All individual AUC values for both analytical methods are shown in Fig. $9 \mathrm{a}-\mathrm{c}$ and it is clear that the same pattern is valid for both 5 and $20 \mathrm{mg}$ doses. The tendency for higher $\mathrm{AUC}_{\text {immuno/ }}$ $\mathrm{AUC}_{\mathrm{LC}-\mathrm{MS} / \mathrm{MS}}$ suggests that the metabolic clearance is higher for the $20 \mathrm{mg}$ dose as the immunoassay method also detects metabolites, which is in accordance with the saturable plasma protein binding and lower clearance of cortisol (hydrocortisone). The $T_{\max }$ values were obtained at the same time points as with the selective LC-MS/MS method, but the $T_{200}$ values appeared earlier for the plasma concentration-time profile based on immunoassay method (Tables 2 and 3; Figs 6 and 7).

\section{Variability of main pharmacokinetic variables measured with both analytical methods}

The CV for $C_{\text {max }}$ for the 5,20 and $20 \mathrm{mg}$ (fed) was 28 , 29 and $49 \%$ respectively, when based on LC-MS/MS (Table 2). The corresponding values for $C_{\max }$ based on the immunoassay were 18,25 and $45 \%$ for the 5,20 and $20 \mathrm{mg}$ (fed) respectively (Table 3 ). The CV for $\mathrm{AUC}_{(0-24 \mathrm{~h})}$ for the 5,20 and $20 \mathrm{mg}$ (fed) was 52, 49 and $48 \%$ respectively, when based on LC-MS/MS (Table 2). The corresponding values for $\mathrm{AUC}_{(0-24 \mathrm{~h})}$ based on the immune assay were 46,43 and $46 \%$ for the 5, 20 and $20 \mathrm{mg}$ (fed) respectively (Table 3).

\section{Discussion}

In an attempt to improve GC replacement therapy a novel oral dual release formulation of hydrocortisone was developed. An outer coating layer with an immediately released fraction of hydrocortisone produced a rapid absorption in the fasting state and, together with the controlled release core, a more extend physiological plasma profile of cortisol was produced that allows for once daily administration. In this study, we investigated the plasma pharmacokinetics of hydrocortisone in healthy subjects after oral administration of an oral dual release single-unit dosage form.

The absorption of hydrocortisone was rapid as the time to reach $200 \mathrm{nmol} / \mathrm{l}$ of cortisol in plasma (based on LC-MS/MS) was 17-20 min for the $20 \mathrm{mg}$ tablet in the fasted state. This plasma concentration can be considered an effective morning cortisol level, as it is the lower limit of normal in many immunoassays. As such, the level is arbitrary, but may at the same time reflect a clinically meaningful end-point. Accordingly, the time to reach $200 \mathrm{nmol} / \mathrm{l}$ was shorter when based on plasma concentrations determined with the immunoassay method. There was no difference in $T_{\max }$ between the 5 and $20 \mathrm{mg}$ tablet in the fasted state and on average it occurred at $\sim 40-50 \mathrm{~min}$ after oral dosing.

Table 3 Plasma pharmacokinetic variables (mean \pm s.D.) of hydrocortisone following oral single dose administration of a novel dosage form $(5$ and $20 \mathrm{mg})$ in fasted $(5$ and $20 \mathrm{mg}$ ) and fed state $(20 \mathrm{mg})$ in healthy subjects $(n=14)$. The calculations of the pharmacokinetic variables are based on plasma concentrations determined with an immunoassay method. All pharmacokinetic variables, except for $T_{\max }$ and $T_{200}$, are presented as geometric mean and 95\% confidence interval, while $T_{\max }$ and $T_{200}$ are reported as median and range.

\begin{tabular}{|c|c|c|c|}
\hline & 5 mg (fasted) & 20 mg (fasted) & 20 mg (fed) \\
\hline $\mathrm{AUC}_{(0-24 \mathrm{~h})}(\mathrm{nmol} \mathrm{h} / \mathrm{l})$ & $1178.8(870.6-1487.1)$ & $3634.0(2739.8-4528.1)$ & $4840.2(3591.2-6089.3)$ \\
\hline$C_{\max }(\mathrm{nmol} / \mathrm{l})$ & $253.1(218.7-287.4)$ & $614.2(555-673.5)$ & $496.1(371.3-621)$ \\
\hline$C(0.25 \mathrm{~h})(\mathrm{nmol} / \mathrm{l})$ & $76.5(42.5-110.4)$ & $98.5(6.40-190.7)$ & $39.0(0-107.3)$ \\
\hline$T_{\max }(\min )$ & $37.5^{\mathrm{a}}(25-90)$ & $45^{\mathrm{b}}(20-90)$ & $105^{a, b}(30-360)$ \\
\hline$T(200 \mathrm{nmol} / \mathrm{l})(\mathrm{min})$ & $26(15-46)$ & $16.2^{\mathrm{C}}(6-35)$ & $25^{\mathrm{c}}(6-130)$ \\
\hline Terminal half-life 5-24 h (h) & $2.99(1.96-4.08)$ & $3.68(1.26-6.10)$ & $2.68(2.10-3.26)$ \\
\hline Terminal half-life 5-14 h (h) & $2.60(2.14-3.05)$ & $3.20(2.46-3.95)$ & $3.20(0-6.63)$ \\
\hline $\mathrm{AUC}_{(0-\text { infinity })}(\mathrm{nmol} \mathrm{h} / \mathrm{l})$ & $1206.6(892.3-1520.9)$ & $3824.8(2660.4-4989.2)$ & 5054.5 (3833.5-6275.5) \\
\hline$\%$ extrapolated AUC (\%) & $1.23(0-2.54)$ & $1.31(0-6.0)$ & $1.13(0-4.56)$ \\
\hline
\end{tabular}

${ }^{\mathrm{a}} P<0.001 ;{ }^{\mathrm{b}} P<0.05 ;{ }^{\mathrm{c}} P<0.05$ (but no significant difference if two extreme values are left out). 


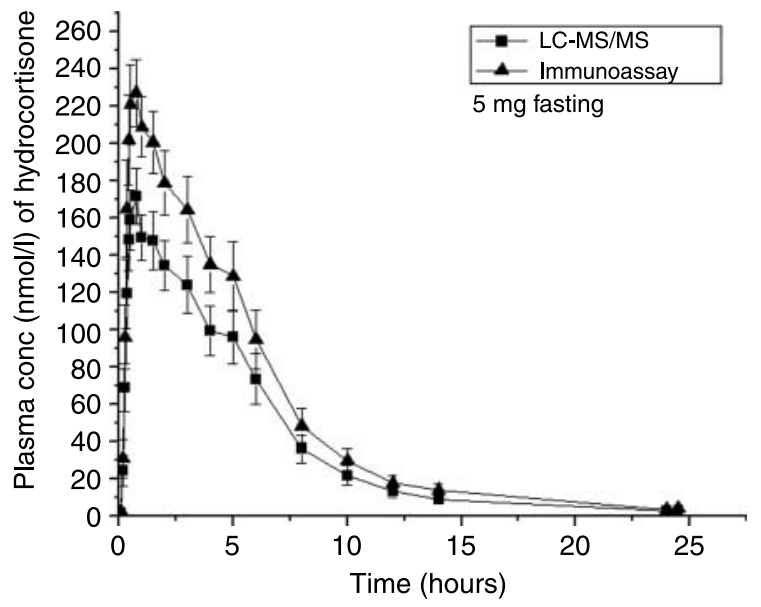

Figure 6 The mean ( \pm S.E.M.) plasma concentration-time profiles for hydrocortisone in healthy subjects $(n=14)$ after single oral administration of novel modified dosage form of $5 \mathrm{mg}$ in the fasted state. The higher plasma curve is based on an immunoassay and the lower of a more selective LC-MS/MS method.

This rapid intestinal absorption is a consequence of the design of the release rate of this novel oral dosage form, as a certain portion of the total dose ( 5 or $20 \mathrm{mg}$ tablet) is released from an immediate release part of the formulation, as well as the favourable biopharmaceutical properties of hydrocortisone itself.

The bioavailability of hydrocortisone after oral administration has been reported to be more than $90 \%$ and the fraction of the dose absorbed is accordingly more than $90 \%(21,22)$. The clearance value of hydrocortisone is, on the other hand, low. Using a selective analytical method (LC-UV) the clearance of hydrocortisone was $209-294 \mathrm{ml} / \mathrm{min}$ after $5-40 \mathrm{mg}$ of intravenous hydrocortisone administration (23).

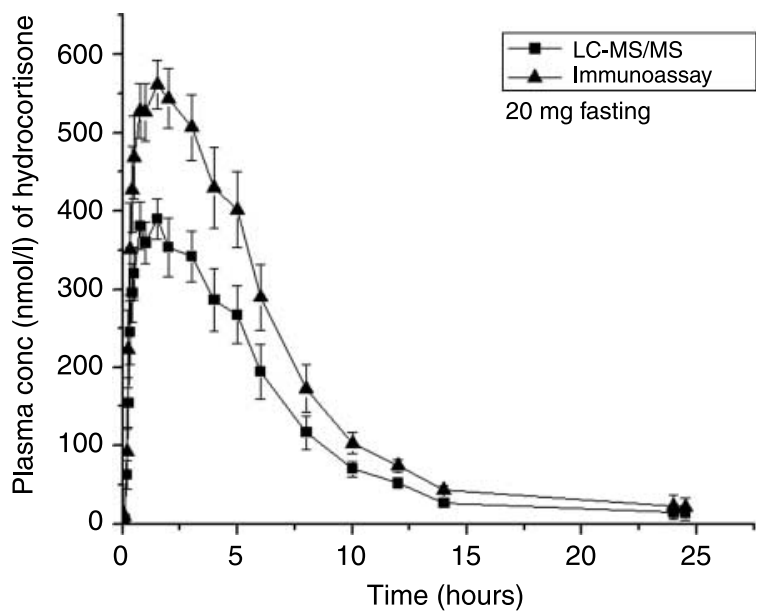

Figure 7 The mean ( \pm S.E.M.) plasma concentration-time profiles for hydrocortisone in healthy subjects $(n=14)$ after single oral administration of novel modified dosage form of $20 \mathrm{mg}$ in the fasted state. The higher plasma curve is based on an immunoassay and the lower of a more selective LC-MS/MS method.
In addition, hydrocortisone has high intestinal permeability in vivo and in vitro $(24,25)$. The intestinal epithelial absorption in vivo is mediated mainly by rapid and passive transcellular diffusion, as hydrocortisone is a poor substrate for apical efflux membrane transporters in the intestinal epithelium, such as P-glycoprotein (25-28). Instead, dissolution rate kinetics in the gastrointestinal lumen is considered to be the ratelimiting step in the rate of intestinal absorption of hydrocortisone even if the solubility of hydrocortisone is in the range of $0.35-0.6 \mathrm{mg} / \mathrm{ml}$ in different media, including human gastrointestinal fluids $(26,29)$. Hydrocortisone is classified as a class II drug according to the biopharmaceutical classification system $(26,29$, 30). As it is a non-proteolyte, its solubility is not strongly affected by $\mathrm{pH}$ in the media (29). This means that the plasma concentration-time profile of hydrocortisone can be controlled by the release rate of the drug from the formulation and that the drug release will not be affected by the $\mathrm{pH}$ differences that exist in various parts of the gastrointestinal system. As the elimination half-life of cortisol is short, the fluctuations in the plasma concentration-time profiles are expected to be highly dependent on the absorption rate.

The dose corrected plasma AUC and $C_{\max }$ values obtained in this study suggest that the absorption and bioavailability is not fully dose proportional in the fasted state. The mean plasma $\mathrm{AUC}_{(0-24 \mathrm{~h})}$ and $C_{\max }$ increased 2.9- and 2.1-fold respectively, when the oral dose of the dual release hydrocortisone increased from 5 to $20 \mathrm{mg}$ in the fasting state. This observation is in accordance with previous reports for conventional immediate release tablets and suspensions of hydrocortisone in the same dose range. The pharmacokinetics of hydrocortisone following single oral doses of 5, 10, 20 and $40 \mathrm{mg}$ hydrocortisone suspensions to healthy male volunteers demonstrated an increase in AUC and $C_{\max }$ with increasing doses, but it was not directly proportional to dose size $(31,32)$. This is most likely due to reduced dissolution rate kinetics of hydrocortisone in the intestinal lumen at the higher dose that will in turn reduce the absorption rate $(23,26,29,31,32)$. The tendency for a decreased plasma exposure at $20 \mathrm{mg}$ compared with $5 \mathrm{mg}$ may also be a consequence of an increased clearance due to saturable plasma protein binding as the clearance of hydrocortisone (a low extraction drug) increases with increasing i.v. doses (23). This increase in clearance might be explained by a non-linear plasma protein binding that could explain the tendency for decreased plasma AUC observed after oral administration at higher doses. This observation cannot be explained by decreased in vivo intestinal permeability since it is high and the transport mechanism of hydrocortisone is mainly by passive diffusion $(25,28,33)$. Moreover, the first-pass metabolic extraction of the parent drug is at most $20 \%$ and is not considered to be able to explain the difference in bioavailability between the 5 and $20 \mathrm{mg}$ doses 


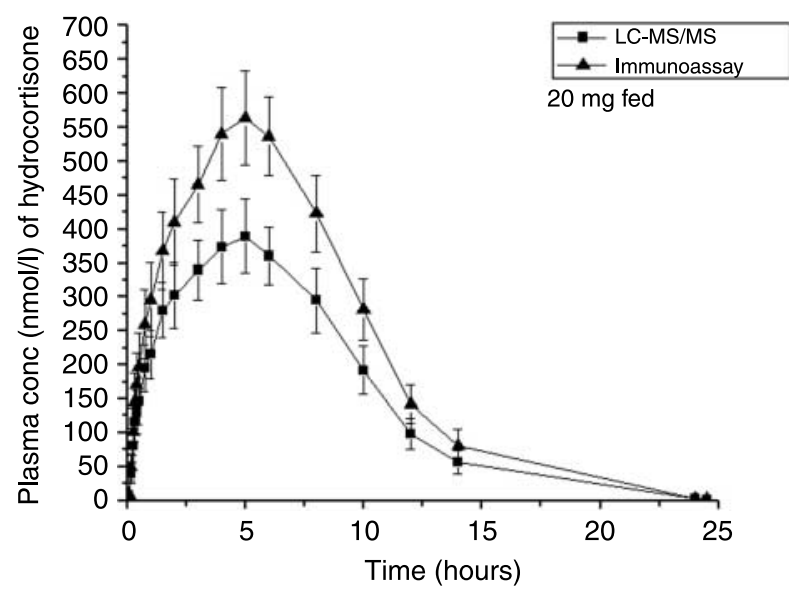

Figure 8 The mean ( \pm S.E.M.) plasma concentration-time profiles for hydrocortisone in healthy subjects $(n=14)$ after single oral administration of novel modified dosage form of $20 \mathrm{mg}$ in the fed state. The higher plasma curve is based on an immunoassay and the lower of a more selective LC-MS/MS method.

$(22,31,32)$. In this study, it was also shown by the use of selective and non-selective immunoassays that more metabolites were formed after oral administration of $20 \mathrm{mg}$. This supports the conclusion that a part of the relative lower exposure of the higher dose is also due to an increased clearance of hydrocortisone, which is a low extraction drug (hormone), due to saturable plasma protein binding.

The $20 \mathrm{mg}$ dose was also given $30 \mathrm{~min}$ after a highcaloric breakfast. Compared with the fasting state, the intestinal absorption $\left(T_{\max }\right)$ of hydrocortisone was delayed by $\sim 60 \mathrm{~min}$ and the time to reach $200 \mathrm{nmol} / \mathrm{l}$ increased by $\sim 9 \mathrm{~min}$ when based on plasma concentrations determined with the immunoassay method. Food delayed the onset of gastrointestinal absorption of hydrocortisone but also showed a tendency to increase the total plasma exposure and bioavailability of hydrocortisone. It is very important from a safety aspect that concomitant food intake will not prevent absorption of hydrocortisone or impact on the predictability and appearance of the resulting plasma cortisol profile. The plasma concentrationtime exposure, $C_{\max }$ and AUC, increased (AUC nonsignificantly) for the $20 \mathrm{mg}$ dose in fed state, and was approximately superimposable with the $5 \mathrm{mg}$ oral dose in fasted state. Altogether this suggests that incomplete dissolution and non-linear increase of clearance is the main reason for the non-linear increase in plasma exposure at increasing oral doses in fasted state. This is in accordance with a biopharmaceutic classification II drug with high intestinal permeability and low solubility $(30,34)$. This is a well-known food-effect for many drugs with similar biopharmaceutical properties to hydrocortisone and has been explained to be due to a higher degree of solubility and the dissolution rate of the drug in the gastrointestinal tract. This observation will be of importance when this new oral dual release formulation is used in replacement therapy of patients with AI. It means that the formulation will be safe and the pharmacokinetic properties can be used in individualising the replacement regime.
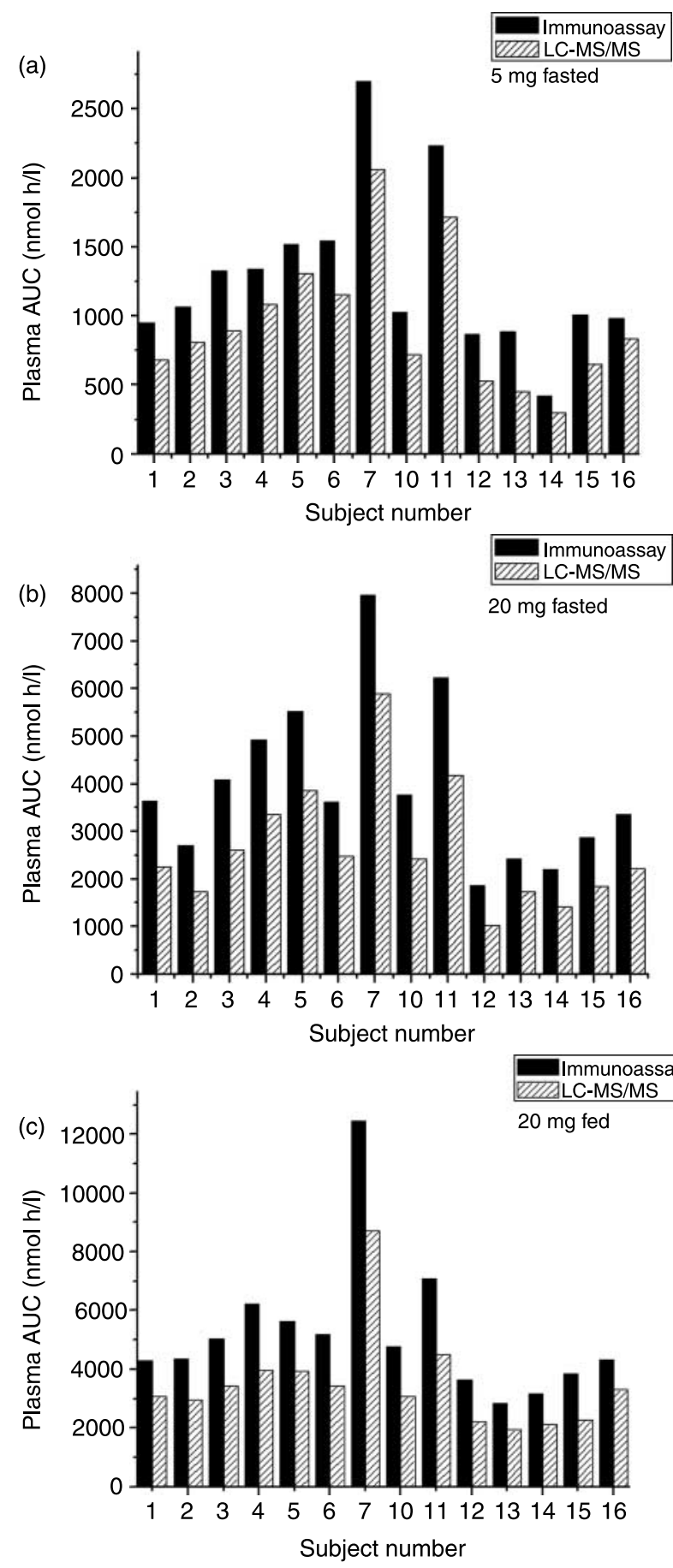

Figure $9(\mathrm{a}-\mathrm{c})$ The individual plasma $\mathrm{AUC}_{0-24}$ for hydrocortisone in healthy subjects $(n=14)$ after single oral administration of novel modified dosage form of $5 \mathrm{mg}$ (fasted), $20 \mathrm{mg}$ (fasted) and $20 \mathrm{mg}$ (fed). The higher plasma $\mathrm{AUC}_{0-24}$ are based on an immunoassay and the lower of a more selective LC-MS/MS method. 
The terminal half-life of hydrocortisone was independent of dose and concomitant intake of food and was about $1.0-1.5 \mathrm{~h}$ longer (i.e. about $2.5-3.5 \mathrm{~h}$ ) than after administration of a conventional tablet $(22,31$, $32,35,36)$. This prolonged terminal half-life is in accordance with the extended release part of this modified release dosage form. The terminal half-life is short enough, however, to provide a cortisol free interval during night, thereby avoiding dose accumulation during long-term replacement therapy. The elimination half-life of cortisol has been reported to be about $1.5 \mathrm{~h}$ following i.v. and oral immediate release dosing $(23,31,32)$. The terminal half-life of endogenous secreted cortisol as approximated from endogenous cortisol plasma concentration-time profiles is longer and in the range of $2.5-4 \mathrm{~h}$ due to the continuous secretion from the adrenal cortex that occurs in a welldefined circadian rhythm $(15,18,37-39)$. This longer half-life of endogenous cortisol means that the plasma pharmacokinetics of endogenous cortisol is secretioncontrolled rather than elimination-controlled.

An important aspect to consider is the analytical method used to assay cortisol when pharmacokinetic data for hydrocortisone/cortisol are evaluated. The most commonly used cortisol assays in clinical studies are immunoassay systems $(35-37,39-41)$. This analytical method cannot fully distinguish between hydrocortisone and formed cortisol metabolites, which is a significant limitation, as hydrocortisone is a drug that is completely metabolised (21). Cortisol is metabolised to its inactive form cortisone and further to dihydrocortisone and tetrahydrocortisone. Other metabolites derived from cortisol include dihydrocortisol, $5 \alpha$-dihydrocortisol, tetrahydrocortisol and $5 \alpha$-tetrahydrocortisol (21). This lack of selectivity means that the immunoassay provides higher plasma concentrations than derived from a more selective analytical method. We demonstrated that the plasma AUC was $40-50 \%$ higher when the immunoassay method was used as compared with the HPLCMS/MS. This confirms the fact that a certain degree of steroid metabolites are included in the analysis and demonstrates the importance of applying selective analytical methods when assessing the pharmacokinetics of a hormone $(20,42)$. This is important to consider when designing new modalities of oral administration of hydrocortisone that will have a first passing across the intestinal wall and through the liver.

Previous studies on normal plasma cortisol profiles demonstrate large variations between individual plasma cortisol levels (43). For instance the peak morning cortisol levels range between $136-720 \mathrm{nmol} / \mathrm{l}$ whereas nadir midnight levels range from $<50-331 \mathrm{nmol} / \mathrm{l}$ showing several fold differences among healthy subjects $(44,45)$. The nadir cortisol concentration varies among studies possibly dependent on the conditions in which these values have been collected. The lowest values reported were collected during sleep in healthy subjects who had acclimatised to the study milieu (46). The study found that during sleep and in an unstressed condition, all healthy subjects had midnight serum cortisol levels below $50 \mathrm{nmol} / \mathrm{l}$. A recent trial using deconvolutional analysis demonstrated variability of $\sim 50 \%$ for mean $24 \mathrm{~h}$ serum cortisol concentration and total cortisol secretion rate (18), variability similar to what was produced with the modified release hydrocortisone formulation studied. The novel dual release oral formulation produced a peak morning level of about $600 \mathrm{nmol} / \mathrm{l}$ with levels $>100 \mathrm{nM}$ during the afternoon and $<50 \mathrm{nM}$ during night time. The bioavailability $(\mathrm{h} \times \mathrm{nmol} / \mathrm{l})$ for the $20 \mathrm{mg}$ tablet both in the fasting and feed state was also similar to the total cortisol exposure, calculated from several different previous publications on the $24 \mathrm{~h}$ endogenous cortisol secretion (43). The tablet administered once therefore mimicked the normal plasma cortisol profile in most aspects except the early morning increase in cortisol that occurs during sleep. Of importance from a safety point of view is the nighttime cortisol free interval, in that it prevents dose accumulation during repeated dosing even if the tablet is administered together with food.

This novel once-daily modified release oral formulation cannot fully mimic the early morning cortisol peak. In the circadian serum cortisol profile a nocturnal rise in serum cortisol occurs 3-5 h after the onset of sleep followed by $\sim 4 \mathrm{~h}$ of high plasma cortisol levels (47). The profile obtained with this new formulation is therefore slightly skewed in time. This was a choice taken in order to produce a safe product with high bioavailability of hydrocortisone with the lowest possible variability. As hydrocortisone is a drug with high intestinal permeability, sufficiently high solubility and rather low dose, the absorption from both small intestine and proximal colon will work well from an orally administered modified release dosage form whereas if it is transferred beyond the proximal colon, absorption failure can occur.

The variability of the main pharmacokinetic variables $C_{\max }$ and $\mathrm{AUC}_{(0-24 \mathrm{~h})}$ based on plasma samples assayed using a LC-MS/MS was similar to what is previously reported from conventional oral formulations of hydrocortisone using immunoassays for cortisol measurements $(35,48)$. The corresponding data for a single dose of 5 or $20 \mathrm{mg}$ (fasted and fed) of dual release hydrocortisone measured with an immunoassay showed a trend towards lower variability. If on the other hand $\mathrm{AUC}_{(0-24 \mathrm{~h})}$ is assessed for a total daily dose administered three times daily, which is the optimised conventional hydrocortisone replacement therapy of today, it is expected that such a therapy would have a much higher variability in the plasma cortisol pharmacokinetics.

A once-a-day administration will most certainly improve compliance to medical therapy as compared with two or three daily administrations (49). It is 
important to point out that the exact degree of benefit has to be determined for an individual therapeutic indication and treatment regime. From a more general health economic perspective, it has also been demonstrated that controlled release dosage forms have a beneficial economic value as increased compliance can be translated to an increase in efficacy (50). Therefore, by improving compliance, severe trough values during the day will decrease. This may in turn reduce the symptoms of GC insufficiency (12) and also prevent any escalation towards adrenal crisis in susceptible patients (5).

The data produced in this study of healthy volunteers demonstrate that the gastrointestinal absorption was rapid, the bioavailability of this hydrocortisone formulation was high and has a variability that is equal to or better than that previously described with conventional immediate release formulations. The food interaction study also demonstrated that the bioavailability increased with food, an important safety aspect. Moreover, there was no single observation of absorption failure in any of the investigated subjects, which suggests that this is a safe once daily oral replacement product. Taken together, this oral formulation has the pharmacokinetic properties allowing it to be taken into clinical trials with AI patients.

\section{Declaration of interest}

R B and A G N have nothing to disclose. G J, H L, T H and S S have equity interests in DuoCort $\mathrm{AB}$.

\section{Funding}

The trial was financially supported by DuoCort AB.

\section{Acknowledgements}

We thank the study personnel at the Clinical Trial Unit, Department of Medicine, Sahlgrenska University Hospital who, with great technical skills, contributed to the trial and Ann-Marie Svensson from IRW Consulting, Gothenburg for trial monitoring. We acknowledge the contribution of Professor Ulf Bondesson and Associate Professor Mikael Hedeland at Statens Veternär Medicinska Anstalt (SVA), Uppsala and Professor Anders Isaksson at Department of Clinical Chemistry, Lund University Hospital in performing the cortisol analysis.

\section{References}

1 Dunlop D. Eighty-six cases of Addison's disease. BMJ 19632 887-891.

2 Mason AS, Meade TW, Lee JA \& Morris JN. Epidemiological and clinical picture of Addison's disease. Lancet 19682 744-747.

3 Rosén T \& Bengtsson B-Å. Premature mortality due to cardiovascular diseases in hypopituitarism. Lancet 1990336 285-288.

4 Tomlinson JW, Holden N, Hills RK, Wheatley K, Clayton RN, Bates AS, Sheppard MC \& Stewart PM. Association between premature mortality and hypopituitarism. West Midlands Prospective Hypopituitary Study Group. Lancet 2001357 425-431.
5 Mills JL, Schonberger LB, Wysowski DK, Brown P, Durako SJ, Cox C, Kong F \& Fradkin JE. Long-term mortality in the United States cohort of pituitary-derived growth hormone recipients. Journal of Pediatrics 2004144 430-436.

6 Bergthorsdottir R, Leonsson-Zachrisson M, Oden A \& Johannsson G. Premature mortality in patients with Addison's disease: a population-based study. Journal of Clinical Endocrinology and Metabolism 200691 4849-4853.

7 Bensing S, Brandt L, Tabaroj F, Sjoberg O, Nilsson B, Ekbom A, Blomqvist P \& Kampe O. Increased death risk and altered cancer incidence pattern in patients with isolated or combined autoimmune primary adrenocortical insufficiency. Clinical Endocrinology $200869697-704$.

8 Peacey SR, Guo CY, Robinson AM, Price A, Giles MA, Eastell R \& Weetman AP. Glucocorticoid replacement therapy: are patients over treated and does it matter? Clinical Endocrinology $1997 \mathbf{4 6}$ 255-261.

9 Dallman MF, Akana SF, Bhatnagar S, Bell ME \& Strack AM. Bottomed out: metabolic significance of the circadian trough in glucocorticoid concentrations. International Journal of Obesity and Related Metabolic Disorders 200024 S40-S46.

10 Dallman MF, la Fleur SE, Pecoraro NC, Gomez F, Houshyar H \& Akana SE. Minireview: glucocorticoids - food intake, abdominal obesity, and wealthy nations in 2004. Endocrinology 2004145 2633-2638.

11 Groves RW, Toms GC, Houghton BJ \& Monson JP. Corticosteroid replacement therapy: twice or thrice daily? Journal of the Royal Society of Medicine $1988 \mathbf{8 1} 514-516$.

12 Hahner S, Loeffler M, Fassnacht M, Weismann D, Koschker AC, Quinkler M, Decker O, Arlt W \& Allolio B. Impaired subjective health status in 256 patients with adrenal insufficiency on standard therapy based on cross-sectional analysis. Journal of Clinical Endocrinology and Metabolism 200792 3912-3922.

13 Lovas K, Loge JH \& Husebye ES. Subjective health status in Norwegian patients with Addison's disease. Clinical Endocrinology $200256581-588$.

14 Gurnell EM, Hunt PJ, Curran SE, Conway CL, Pullenayegum EM, Huppert FA, Compston JE, Herbert J \& Chatterjee VK. Long-term DHEA replacement in primary adrenal insufficiency: a randomized, controlled trial. Journal of Clinical Endocrinology and Metabolism 200893 400-409.

15 Lovas K \& Husebye ES. Continuous subcutaneous hydrocortisone infusion in Addison's disease. European Journal of Endocrinology 2007157 109-112.

16 Reynolds RM, Stewart PM, Seckl JR \& Padfield PL. Assessing the HPA axis in patients with pituitary disease: a UK survey. Clinical Endocrinology $2006 \mathbf{6 4} 82-85$.

17 Filipsson H, Monson JP, Koltowska-Haggstrom M, Mattsson A \& Johannsson G. The impact of glucocorticoid replacement regimens on metabolic outcome and comorbidity in hypopituitary patients. Journal of Clinical Endocrinology and Metabolism 200691 3954-3961.

18 Darzy KH \& Shalet SM. Absence of adrenocorticotropin (ACTH) neurosecretory dysfunction but increased cortisol concentrations and production rates in ACTH-replete adult cancer survivors after cranial irradiation for nonpituitary brain tumors. Journal of Clinical Endocrinology and Metabolism 200590 5217-5225.

19 Lennernas H, Skrtic S \& Johannsson G. Replacement therapy of oral hydrocortisone in adrenal insufficiency: the influence of gastrointestinal factors. Expert Opinion on Drug Metabolism \& Toxicology 20084 749-758.

20 Shah VP, Midha KK, Findlay JW, Hill HM, Hulse JD, McGilveray IJ, McKay G, Miller KJ, Patnaik RN, Powell ML, Tonelli A, Viswanathan CT \& Yacobi A. Bioanalytical method validation a revisit with a decade of progress. Pharmaceutical Research 2000 17 1551-1557.

21 Czock D, Keller F, Rasche FM \& Haussler U. Pharmacokinetics and pharmacodynamics of systemically administered glucocorticoids. Clinical Pharmacokinetics 200544 61-98. 
22 Derendorf H, Mollmann H, Barth J, Mollmann C, Tunn S \& Krieg M. Pharmacokinetics and oral bioavailability of hydrocortisone. Journal of Clinical Pharmacology 199131 473-476.

23 Toothaker RD \& Welling PG. Effect of dose size on the pharmacokinetics of intravenous hydrocortisone during endogenous hydrocortisone suppression. Journal of Pharmacokinetics and Biopharmaceutics $198210147-156$.

24 Lennernas $H$. Intestinal permeability and its relevance for absorption and elimination. Xenobiotica 200737 1015-1051.

25 Schedl HP. Absorption of steroid hormones from the human small intestine. Journal of Clinical Endocrinology and Metabolism 196525 1309-1316.

26 Naylor LJ, Bakatselou V \& Dressman JB. Comparison of the mechanism of dissolution of hydrocortisone in simple and mixed micelle systems. Pharmaceutical Research 199310 865-870.

27 Ueda K, Okamura N, Hirai M, Tanigawara Y, Saeki T, Kioka N, Komano T \& Hori R. Human P-glycoprotein transports cortisol, aldosterone, and dexamethasone, but not progesterone. Journal of Biological Chemistry $199226724248-24252$.

28 Yates CR, Chang C, Kearbey JD, Yasuda K, Schuetz EG, Miller DD, Dalton JT \& Swaan PW. Structural determinants of P-glycoprotein-mediated transport of glucocorticoids. Pharmaceutical Research 200320 1794-1803.

29 Pedersen BL, Brondsted H, Lennernas H, Christensen FN, Mullertz A \& Kristensen HG. Dissolution of hydrocortisone in human and simulated intestinal fluids. Pharmaceutical Research 200017 183-189.

30 Amidon GL, Lennernas H, Shah VP \& Crison JR. A theoretical basis for a biopharmaceutic drug classification: the correlation of in vitro drug product dissolution and in vivo bioavailability. Pharmaceutical Research 199512 413-420.

31 Toothaker RD, Craig WA \& Welling PG. Effect of dose size on the pharmacokinetics of oral hydrocortisone suspension. Journal of Pharmaceutical Sciences 198271 1182-1185.

32 Toothaker RD, Sundaresan GM, Hunt JP, Goehl TJ, Rotenberg KS, Prasad VK, Craig WA \& Welling PG. Oral hydrocortisone pharmacokinetics: a comparison of fluorescence and ultraviolet high-pressure liquid chromatographic assays for hydrocortisone in plasma. Journal of Pharmaceutical Sciences 198271 573-576.

33 Faassen F, Kelder J, Lenders J, Onderwater R \& Vromans H. Physicochemical properties and transport of steroids across Caco-2 cells. Pharmaceutical Research 200320 177-186.

34 Lennernas H \& Abrahamsson B. The use of biopharmaceutic classification of drugs in drug discovery and development: current status and future extension. Journal of Pharmacy and Pharmacology 200557 273-285.

35 Mah PM, Jenkins RC, Rostami-Hodjegan A, Newell-Price J, Doane A, Ibbotson V, Tucker GT \& Ross RJ. Weight-related dosing, timing and monitoring hydrocortisone replacement therapy in patients with adrenal insufficiency. Clinical Endocrinology 200461 367-375.

36 Newell-Price J, Whiteman M, Rostami-Hodjegan A, Darzy K, Shalet S, Tucker GT \& Ross RJ. Modified-release hydrocortisone for circadian therapy: a proof-of-principle study in dexamethasonesuppressed normal volunteers. Clinical Endocrinology $2008 \mathbf{6 8}$ 130-135.

37 Blomgren J, Ekman B, Andersson PO \& Arnqvist HJ. Non-physiological levels of circulating cortisol in growth hormone-treated hypopituitary adults after conventional cortisone substitution. Scandinavian Journal of Clinical and Laboratory Investigation 200464 132-139.

38 Esteban NV, Loughlin T, Yergey AL, Zawadzki JK, Booth JD, Winterer JC \& Loriaux DL. Daily cortisol production rate in man determined by stable isotope dilution/mass spectrometry. Journal of Clinical Endocrinology and Metabolism 1991 72 39-45.

39 Merza Z, Rostami-Hodjegan A, Memmott A, Doane A, Ibbotson V, Newell-Price J, Tucker GT \& Ross RJ. Circadian hydrocortisone infusions in patients with adrenal insufficiency and congenital adrenal hyperplasia. Clinical Endocrinology 200665 45-50.

40 Kraan GP, Dullaart RP, Pratt JJ, Wolthers BG, Drayer NM \& De Bruin R. The daily cortisol production reinvestigated in healthy men. The serum and urinary cortisol production rates are not significantly different. Journal of Clinical Endocrinology and Metabolism $1998 \mathbf{8 3} 1247-1252$.

41 Linder BL, Esteban NV, Yergey AL, Winterer JC, Loriaux DL \& Cassorla F. Cortisol production rate in childhood and adolescence. Journal of Pediatrics 1990117 892-896.

42 Karnes HT, Shiu G \& Shah VP. Validation of bioanalytical methods. Pharmaceutical Research 1991 8 421-426.

43 Debono M, Ghobadi C, Rostami-Hodjegan A, Huatan H, Campbell MJ, Newell-Price J, Darzy K, Merke DP, Arlt W \& Ross RJ. Modified-release hydrocortisone to provide circadian cortisol profiles. Journal of Clinical Endocrinology and Metabolism $2009941548-1554$.

44 Horrocks PM, Jones AF, Ratcliffe WA, Holder G, White A, Holder R, Ratcliffe JG \& London DR. Patterns of ACTH and cortisol pulsatility over twenty-four hours in normal males and females. Clinical Endocrinology 199032 127-134.

45 Wallace WH, Crowne EC, Shalet SM, Moore C, Gibson S, Littley MD \& White A. Episodic ACTH and cortisol secretion in normal children. Clinical Endocrinology $199134215-221$.

46 Newell-Price J, Trainer P, Perry L, Wass J, Grossman A \& Besser M. A single sleeping midnight cortisol has $100 \%$ sensitivity for the diagnosis of Cushing's syndrome. Clinical Endocrinology 199543 545-550.

47 Weitzman ED, Fukushima D, Nogeire C, Roffwarg H, Gallagher TF \& Hellman L. Twenty-four hour pattern of the episodic secretion of cortisol in normal subjects. Journal of Clinical Endocrinology and Metabolism 197133 14-22.

48 Thomson AH, Devers MC, Wallace AM, Grant D, Campbell K, Freel M \& Connell JM. Variability in hydrocortisone plasma and saliva pharmacokinetics following intravenous and oral administration to patients with adrenal insufficiency. Clinical Endocrinology $200766789-796$.

49 Osterberg L \& Blaschke T. Adherence to medication. New England Journal of Medicine 2005353 487-497.

50 Cramer MP \& Saks SR. Translating safety, efficacy and compliance into economic value for controlled release dosage forms. PharmacoEconomics 19945 482-504.

Received 15 April 2009

Accepted 18 April 2009 